"Mircea cel Batran" Naval Academy Scientific Bulletin, Volume XIX - 2016 - Issue 2 The journal is indexed in: PROQUEST / DOAJ I Crossref / EBSCOhost / INDEX COPERNICUS I DRJI / OAJI I JOURNAL INDEX I I2OR / SCIENCE LIBRARY INDEX / Google Scholar / Academic Keys/ ROAD Open Access I Academic Resources / Scientific Indexing Services / SCIPIO / JIFACTOR

\title{
LIGHT POLLUTION IN CONSTANTA: A CASE STUDY
}

\author{
Andrei POCORA ${ }^{1}$ \\ Sergiu LUPU ${ }^{2}$ \\ Alecu TOMA ${ }^{3}$ \\ Cosmin KATONA ${ }^{4}$
}

${ }^{1}$ Assistant Professor eng., PhD student, "Mircea cel Batran" Naval Academy, Constanta, Romania andrei.pocora@anmb.ro

${ }^{2}$ Lecturer eng. PhD, "Mircea cel Batran" Naval Academy, Constanta, Romania sergiu.lupu@anmb.ro

${ }^{3}$ Adv. Instructor, PhD, "Mircea cel Batran" Naval Academy, Constanta, Romaniaalecu.toma@anmb.ro

${ }^{4}$ Asisstant Professor eng. PhD student, University Politehnica, Bucharest, Romania katona.cosmin@yahoo.ro

\begin{abstract}
Light pollution, also known as luminous pollution or photopollution, is the result of inefficient, misdirected or excessive artificial light and can cause a series of problems. Being a side effect of industrial civilization, its sources include urban lightening, advertising LED panels, streetlights, mainly all sorts of artificial illumination. The main consequences of light pollution include energy waste, security problems, health problems, disruption of ecosystems and negative effects on astronomy. More artificial light means an increased sky glow, thus fewer stars are visible on the night sky. Being a real threat to our ecosystem, various organizations started monitoring light pollution and began researching different ways to reduce its impact on Earth.

The worldwide light pollution map is still in a continuous developing state and from that point of view Romania could have a great potential to carry out new maps for the young astronomical associations.

Starting with 2015 "Mircea cel Batran" Naval Academy is endowed with a Sky Quality Meter, a professional tool used to measure light pollution. Various measurements were taken on site with this tool, and a database was created. This paper is a case study on light pollution in Constanta city and aims to find the best places for astronomical observations.
\end{abstract}

Keywords: light pollution, astronomy, sky quality, artificial light

\section{INTRODUCTION}

Light pollution is the alteration of night natural lighting levels caused by anthropogenic sources of light [1]. This alteration of light is usually the result of inefficient or excessive artificial light.

Since the first electric light bulb was invented only 160 ago, this is quite a new phenomenon. Since artificial light has become a part of our everyday life, light emissions tend to grow at an alarming rate. There are areas in densely populated areas where dark skies are very rare and stars cannot be seen. The International DarkSky Association estimates that nowadays only a $5^{\text {th }}$ of the world population can clearly see the Milky Way with the naked eye.

With the help of modern technology and the use of satellites, NASA started to publish various images of Earth at night (Figure 1).

It can easily be seen that densely populated areas such as Europe, United States and Japan are highly affected by light pollution while most parts of Australia, Africa and South America have darker skies. In Europe, the eastern part seems to be less affected by light pollution (Figure 2).

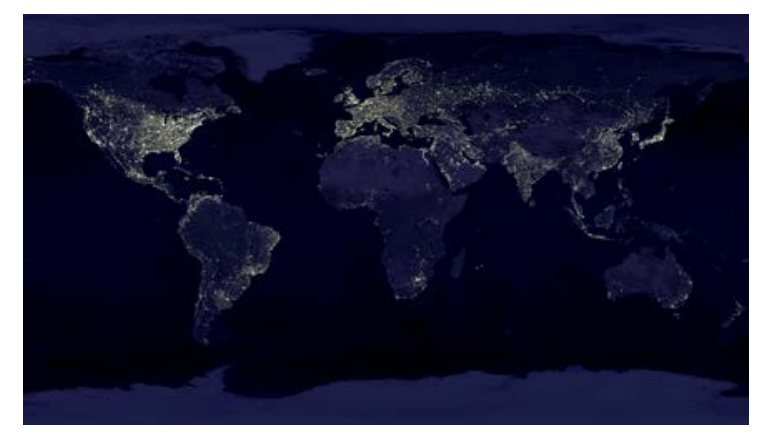

Fig. 1 - Earth at night. Recorded by the Defense MeteorologicalSatellite Program (DMSP) OperationalLinescan System (OLS). NASA (2014)

(c) 2015. This work is licensed under the Creative Commons Attribution-Noncommercial-Share Alike 4.0 License. 
"Mircea cel Batran" Naval Academy Scientific Bulletin, Volume XIX - 2016 - Issue 2 The journal is indexed in: PROQUEST / DOAJ I Crossref / EBSCOhost / INDEX COPERNICUS I DRJI / OAJI I JOURNAL INDEX / I2OR / SCIENCE LIBRARY INDEX / Google Scholar / Academic Keys/ ROAD Open Access I Academic Resources / Scientific Indexing Services / SCIPIO / JIFACTOR

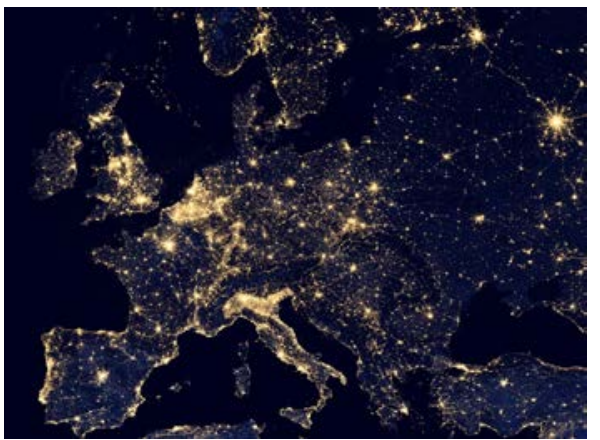

Fig. 2 - Europe at night

\section{TYPES OF LIGHT POLLUTION}

The term light pollution refers to multiple problems occurring from inefficient, misdirected or excessive artificial light. Various types of light pollution include over-illumination, glare, sky-glow, light clutter and light trespass. Usually the result of an inefficient light source can be in more than one of these categories.

\subsection{Over-illumination}

Over-illumination represents the excessive use of light (Figure 3). This is also the main cause for wasted energy and large amounts of money spent on inefficient lightning.

Several factors that cause this phenomenon are as follows:

- Incorrect choice of light bulbs and lamp used for street illumination;

- Lack of timers and sensors that can put off light when not needed;

- Massive use of LED panels for publicity during night-time;

- Lack of illumination maintenance;

- Lack of public awareness.

Most of these factors can be easily cleared with available technology and without many costs.

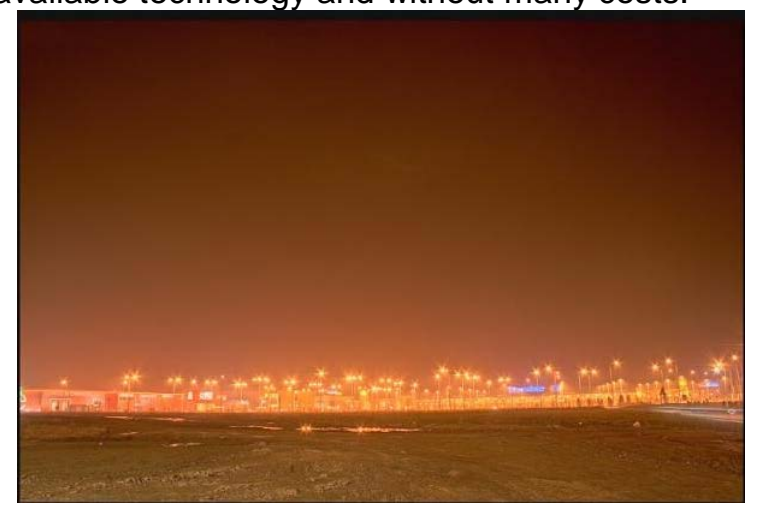

Fig. 3 Over-illumination

\subsection{Glare}

Glare (Figure 4) is the result of high contrast between dark areas and light resulting from a

DOI: 10.21279/1454-864X-16-12-011

(c) 2015. This work is licensed under the Creative Commons Attribution-Noncommercial-Share Alike 4.0 License. source of light. For example, glare can be experienced by looking into the filament of a lit lightbulb. Different types of glare that affect the environment are:

- blinding glare;

- disability glare;

- discomfort glare.

Usually this type of pollution affects road safety as it makes it hard for the human eye to adjust to brightness and obscure night vision.

Depending on the intensity of the glare the human eye can re-adjust to darkness on a period starting from several minutes up to an hour of exposure.

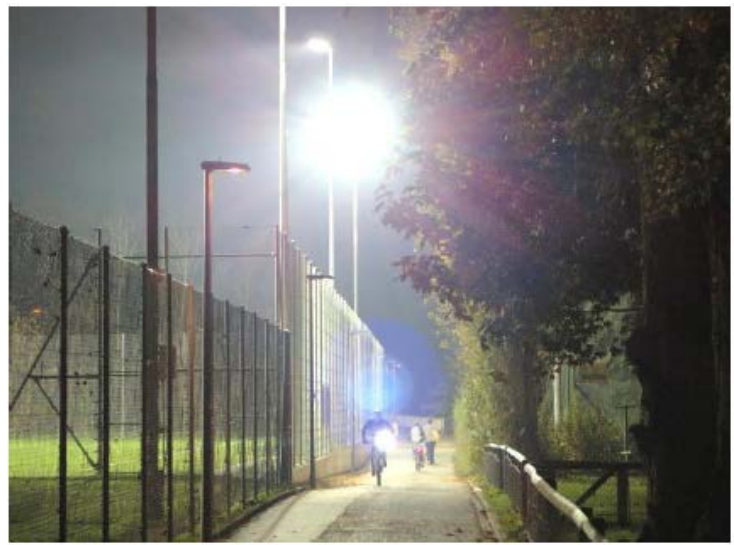

Fig. 4 Glare

\subsection{Sky-glow}

Sky-glow (Figure 5) or simply glow, is the effect of light pollution that can be easily seen from all populated areas. It can be described as an orange cloud that lays above highly populated areas.

Sky-glow is the result of all light reflected and is related to the wavelength of the light. This type of light pollution is the one affecting the most astronomical observations. Due to it, the contrast in the night sky is reduced which makes it impossible to see faint stars or objects. Sky-glow is also the main reason why astronomical observatories are built in remote areas, at high altitudes or in areas with restrictions to light emissions.

The only effective method to reduce sky-glow is by choosing the right lighting fixtures, so that the emitted light is directed towards the earth and use of appropriate light bulbs. 
"Mircea cel Batran" Naval Academy Scientific Bulletin, Volume XIX - 2016 - Issue 2 The journal is indexed in: PROQUEST I DOAJ / Crossref / EBSCOhost / INDEX COPERNICUS / DRJI / OAJI I JOURNAL INDEX I I2OR / SCIENCE LIBRARY INDEX / Google Scholar / Academic Keys/ ROAD Open Access I Academic Resources / Scientific Indexing Services / SCIPIO / JIFACTOR

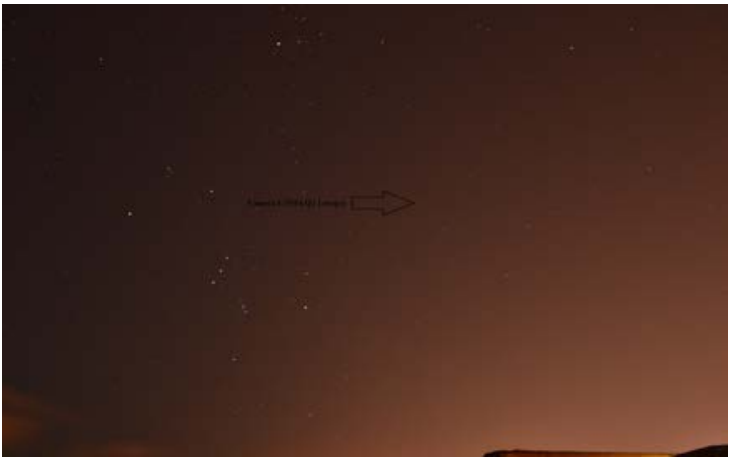

Figure 5. Comet C/2014 Q2 Lovejoy as seen from Constanta with sky-glow

\subsection{Light clutter}

Light clutter refers to excessive grouping of lights that can cause confusion and is usually present on badly designed road illumination.

\subsection{Light trespass}

Light trespass refers to unwanted light that enters one's property (light passing through fences, trees). This part of light pollution directly affects people during night-time by sleep deprivation. Main causes for light trespass are the height of light poles and recently the excessive use of publicity LED panels in cities.

\section{CONSEQUENCES OF LIGHT POLLUTION}

Since light pollution is a term recently introduced, research in this field is still in its early days. It is obvious that inefficient and excessive lightning leads to an increased amount of energy waste. Lighting is responsible for one-fourth of all energy consumption worldwide, and case studies have shown that several forms of over-illumination constitute energy wastage, including nonbeneficial upward direction of nighttime lighting. On a global scale, approximately $19 \%$ of all electricity used, produces light at night [2]. Other impacts of light pollution affect the animal kingdom, vegetable kingdom and mankind.

The most known impact of this kind of pollution is known by the astronomers since early days, by the increased brightness of the night sky (Figure 6 ). This makes it very difficult or impossible to observe faint stars and objects. Although astronomers can use various filters to reduce light pollution, this can affect the color perception. Also, measurement of variable stars is affected.

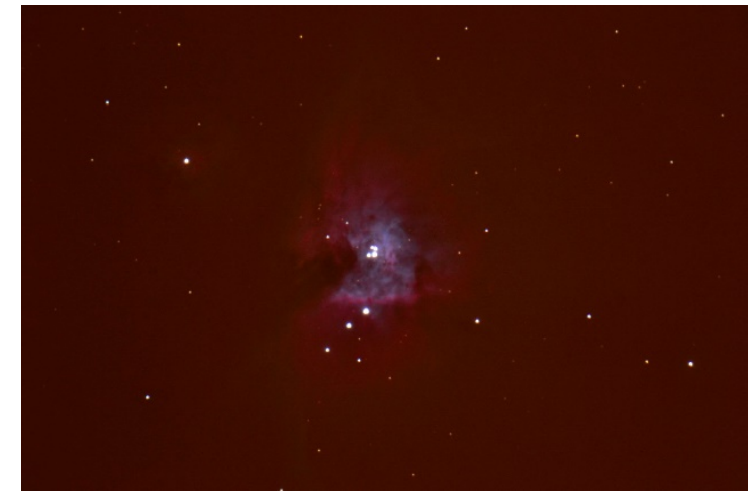

Figure 6. M42 (Orion nebulae) seen from a sky affected by light pollution

To reduce the impact on observational astronomy, newer telescopes and domes are built in remote areas, at high altitudes or in areas with restrictions to light emissions.

Light trespass and glare also affect astronomical observations because the light may enter the telescope's tube and reflect on the mirrors. The impact can be reduced by placing the telescope inside a dome, by installing light shields on light bulbs nearby or by changing the observers position.

Nevertheless, no matter what method is used, the sky will still differ from one that is totally unaffected by light pollution.

\section{DATA AQUIRING}

Starting with 2015 "Mircea cel Bătrân" Naval Academy is endowed with a Sky Quality Meter (Figure 7), a professional tool used to measure light pollution.
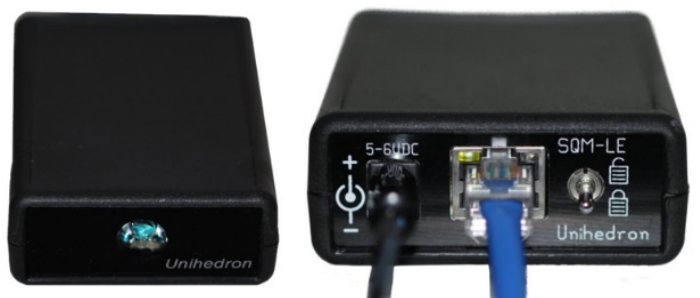

Fig. 7 SMQ-LE

SQM-LE is a meter for measuring sky brightness used by astronomers. It provides readings in magnitudes per square arcsecond noted as mpsas. Mpsas is a logarithmic measurement which leads to large changes of sky brightness for small numerical changes. Magnitude is an astronomical unit used for measuring the brightness of an object. The larger the number gets, the fainter the object is. For example, the Sun has -26.73 magnitude, Full Moon has -12.6 magnitude, star Vega has +0.03 magnitude, the faintest stars observable with the naked eye have +6 magnitude while the faintest objects observable with Hubble Space Telescope have 
"Mircea cel Batran" Naval Academy Scientific Bulletin, Volume XIX - 2016 - Issue 2 The journal is indexed in: PROQUEST I DOAJ / Crossref / EBSCOhost / INDEX COPERNICUS / DRJI / OAJI I JOURNAL INDEX / I2OR / SCIENCE LIBRARY INDEX / Google Scholar / Academic Keys/ ROAD Open Access I Academic Resources / Scientific Indexing Services / SCIPIO / JIFACTOR

+30 magnitude [3]. An interpretation of SQM readings and the brightness of the night sky is given in Figure 8.

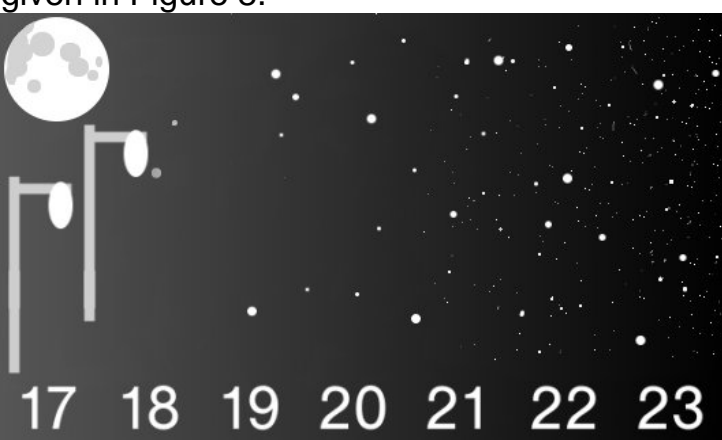

Fig. 8 Mpsas scale

The highest value obtained world-wide with the help of SQM was 21.80 Mpsas.

The aim of the study was to see if "Mircea cel Batran" Naval Academy is a potential site for astronomical observations and to create a database with SQM readings in Constanta (Figure 9).

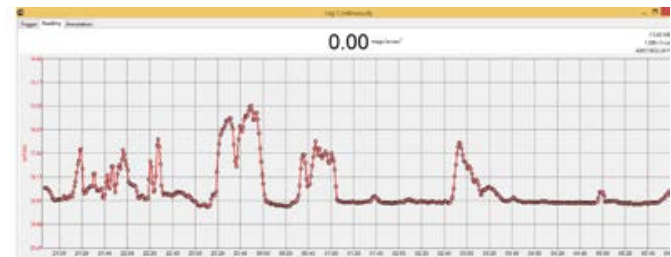

Fig. 9 SQM readings in Mircea cel Batran Naval Academy

Until now in Romania only a few measurements were taken of which none was taken in Dobrogea region (Figure 10), leading to another pioneering activity for "Mircea cel Batran" Naval Academy.

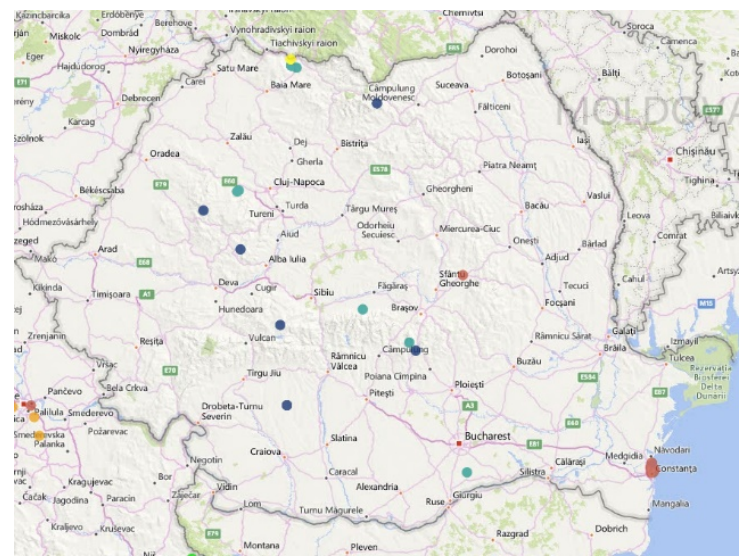

Fig. 10 SQM readings in Romania
The setup used for data acquisition is shown in Figure 11 [3].

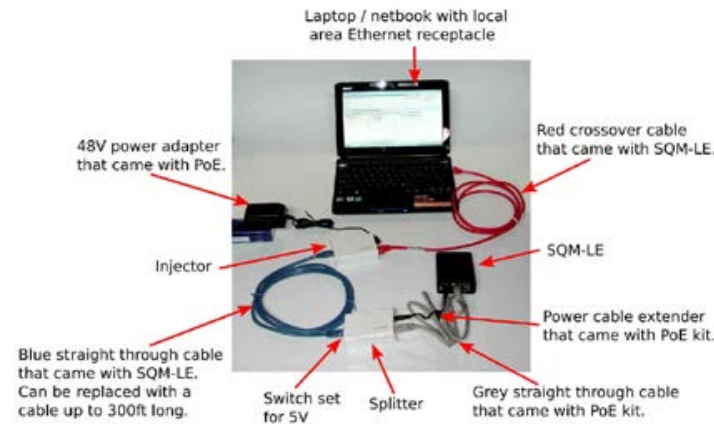

Fig. 11 Setup used for data acquisition

\section{RESULTS}

Using SQM-LE, more than 4500 recordings were stored in different places from Constanta (Figures 12, 13).

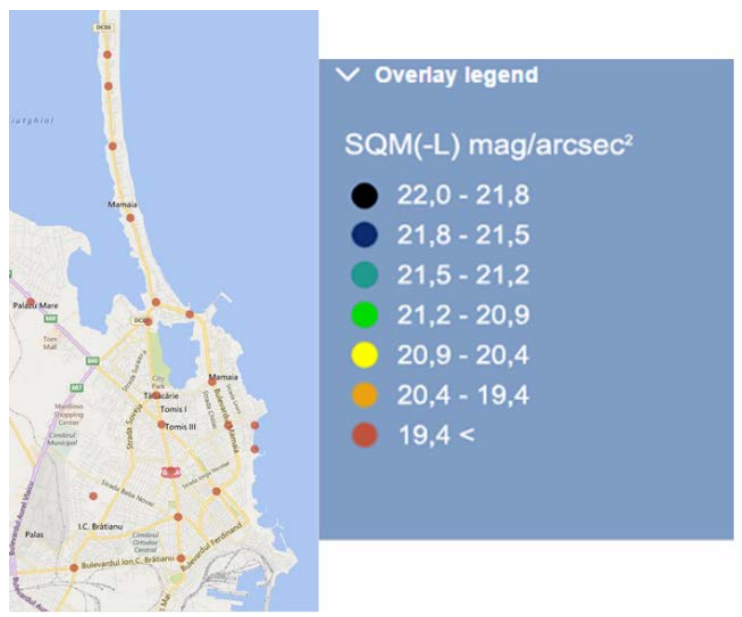

Fig. 12 Places is Constanta where SQM readings were made.

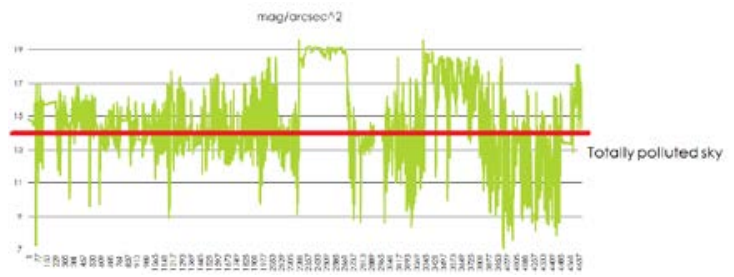

Fig 13. SQM recordings for Constanta

\section{CONCLUSIONS}

Analyzing the results led to the following conclusions:

- the mean value of light pollution for Constanta is 14.52 Mpsas;

- $\quad$ the maximum obtained value was 19.02 Mpsas;

(c) 2015. This work is licensed under the Creative Commons Attribution-Noncommercial-Share Alike 4.0 License. 
"Mircea cel Batran" Naval Academy Scientific Bulletin, Volume XIX - 2016 - Issue 2 The journal is indexed in: PROQUEST I DOAJ / Crossref / EBSCOhost / INDEX COPERNICUS / DRJI / OAJI I JOURNAL INDEX I I2OR / SCIENCE LIBRARY INDEX / Google Scholar / Academic Keys/ ROAD Open Access I Academic Resources / Scientific Indexing Services / SCIPIO / JIFACTOR

- the most suitable area for astronomical observations is on the shore of the Black Sea;

- the most polluted area is near the port;

- the mean value acquired in "Mircea cel Batran Naval" Academy was 18.47 Mpsas;

- the sky-glow in Constanta is a consequence of the lighting in Constanta port.

\section{BIBLIOGRAPHY}

[1] P. Cinzano, F. Falchi, C. D. Elvidge, K. E. Baugh, The artificial night sky brightness mapped from DMSP satellite Operational Linescan System measurements. Mon. Not. R. Astron. Soc. 318, 641-657 (2000)

[2] Dr. Rasna Rajkhowa., Light Pollution and Impact of Light Pollution. International Journal of Science and Research (IJSR), Vol 3 Issue 10, 2014

[3] ***, SQM-LE Operator's Manual, Unihedron, 2015

[4] Stefan M. Bruehlmann, Measuring and Mapping Light Pollution at a LocalScale, Vrije Universiteit Amsterdam, 2014

[5] Birriel, J., Wheatley, J. \& McMichael, C, Documenting Local Night Sky Brightness Using Sky Quality, The Journal of the American Association of Variable Star Observers (JAAVSO), 2010

[6] S. Lupu, A. Pocora, C. Katona et all, Studiu privind pregătirea, efectuarea și înregistrarea observațiilor astronomice în cadrul Observatorului Astronomic al Academiei Navale Mircea cel Bătrân, NRCD

08.1020/18.10.2016 